\title{
Produtividade de massa verde de milho transgênico em função do arranjo populacional na região do Cariri, CE
}

Productivity of transgenic corn green mass in the function of the population arrangement in the Cariri, CE region

\section{Productivité des masse verte des maïs transgénique en fonction de la arrangement population dans région Cariri, CE} \author{
población em Cariri, CE región \\ Rivanildo Júnior da Silva Soares ${ }^{1}$ \\ Antonio Alves Pinto ${ }^{1}$ \\ Felipe Thomaz da Camara ${ }^{1}$ \\ Laudeline Dantas Santana ${ }^{1}$
}

Productividad de masa verde de maíz transgénico en función de arreglo de la

Recebido em 23/11/2016; revisado e aprovado em 15/04/2017; aceito em 19/04/2017.

DOI: http://dx.doi.org/10.20435/inter.v18i2.1444

\begin{abstract}
Resumo: O objetivo deste artigo foi avaliar a produtividade de massa verde de dois híbridos transgênicos de milho submetidos a diferentes arranjos populacionais, na Universidade Federal do Cariri (UFCA), em Crato, CE. Por meio dos resultados obtidos, nota-se que o milho transgênico Yeld Gard e o Feroz Víptera obtiveram resultados semelhantes e que os menores espaçamentos utilizados proporcionaram melhor aproveitamento da área, elevando a produtividade de massa verde total.
\end{abstract}

Palavras-chave: densidade; cultivares; massa verde.

Abstract: This article aimed to evaluate the green mass productivity of two transgenic hybrids maize under different population arrangements, in the Universidade Federal do Cariri (UFCA), in Crato, CE. Through the results, we note that the transgenic corn Yeld Gard and the Feroz Víptera obtained similar results and that the smallest spacings used provided the best use of the area, increasing the total green mass productivity. Key words: density; cultivars; green mass.

Résumé: Le objectif de cet article était d'évaluer le rendement de masse verte de deux hybrides de maïs transgéniques, sous différents arrangements de la population, dans Universidade Federal do Cariri (UFCA), dans Crato, CE. Grâce aux résultats obtenus, notez que le maïs transgénique Yeld Gard et Feroz Viptera a obtenu des résultats similaires et que les plus petits espacements utilisés à condition que la meilleure utilisation de la zone, élevage la productivité totale de masse verte.

Mots-clés: densité; cultivar; masse verte.

Resumén: El objetivo de este artículo fue evaluar el rendimiento de masa verde de dos híbridos de maíz transgénico bajo diferentes arreglos de población, en la Universidade Federal do Cariri (UFCA) en Crato, CE. A través de los resultados obtenidos, se observa que el maíz transgénico Yeld Gard y Feroz Víptera obtuvieron resultados similares y que los espaciamientos más pequeños se utilizan siempre el mejor uso de la zona, creciente de la productividad de masa verde total.

Palabras clave: densidad; la variedad; la masa verde.

\section{INTRODUÇÃO}

O milho é um cereal utilizado na alimentação humana e na fabricação de vários subprodutos, principalmente na alimentação animal, sendo oferecido em grãos, ou em rações formuladas e balanceadas. Devido a isso, 70 a $80 \%$ da produção desse cereal é diretamente empregada na

\footnotetext{
${ }^{1}$ Universidade Federal do Cariri (UFCA), Crato, Ceará, Brasil.
} 
composição de rações para produção de proteína de origem animal como carne, leite e ovos (ALVES et al., 2015).

Devido à tradição do cultivo, a elevada produtividade e o bom valor nutritivo, o milho é a cultura tomada como padrão para a produção de silagem. Junto a isso, o uso de híbridos adaptados às condições de um local é responsável pelo aumento na produtividade dessa cultura (PAZIANI et al., 2009)

A produção de massa verde de uma cultivar é um dos primeiros critérios a ser avaliado quando a intenção é saber a qualidade da planta, preocupação essa que deve ser tomada antes mesmo de avaliar a qualidade da silagem; é também um parâmetro para o dimensionamento dos silos (FERRARI JUNIOR et al., 2005).

De acordo com Sangoi (2000), para conseguir atingir o potencial máximo de produção do milho, vários fatores estão relacionados, como a disponibilidade hídrica, boas condições de fertilidade do solo, ciclo da cultivar, espaçamento, época de semeadura e uma população variando entre 30.000 a 90.000 plantas por ha ${ }^{-1}$. A cultura é muito sensível à variação na densidade de plantas. Para cada sistema de produção, existe uma população que maximiza o rendimento de grãos (CRUZ et al., 2000).

A redução de espaçamento de 0,9 para 0,45 m, mantendo a população de plantas, favorece a produção de silagem a partir de milho safrinha, com isso verifica-se que apenas a redução do espaçamento sem alteração na população nem da adubação, pode promover ganho de até 175\% na produção da massa verde (GUARESCHI et al., 2008).

As maiores produtividades de massa verde encontradas na literatura para o milho, flutuam entre 31,37 a 44,96 t ha ${ }^{-1}$ (FERRARI JUNIOR et al., 2005; MENDES et al., 2006). Porém Paziani et al. (2009) conseguiram produtividade média de massa verde de 50,47 $\mathrm{t} \mathrm{ha}^{-1}$.

Dessa forma, o presente artigo teve por objetivo avaliar a produtividade de massa verde do milho transgênico em função da cultivar e do arranjo entre as plantas na região do Cariri cearense em sistema irrigado por microaspersão.

\section{MATERIAL E MÉTODOS}

O experimento foi conduzido na área experimental do Centro de Ciências Agrárias e da Biodiversidade (CCAB), da Universidade Federal do Cariri (UFCA), em Crato, CE, localizado a 507 $\mathrm{km}$ da cidade de Fortaleza, CE, no período de agosto a novembro de 2015. Geograficamente,

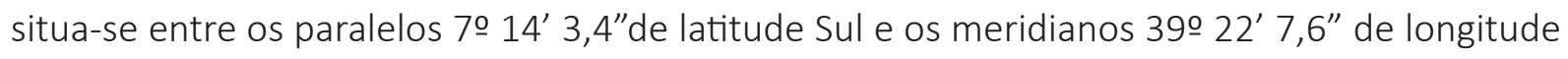
Oeste, a 442 metros de altitude.

O solo da área experimental é classificado como um Argissolo Vermelho Amarelo (FUNDAÇÃO CEARENSE DE METEOROLOGIA E RECURSOS HÍDRICOS [FUNCEME], 2012), de relevo suave ondulado e textura franco-arenosa. A constituição química na camada de $0-20 \mathrm{~cm}$ foram: $\mathrm{pH}\left(1: 2,5 \mathrm{H}_{2} \mathrm{O}\right.$ ): 4,3; P (melich-1): 7,0 mg dm${ }^{-3} ; \mathrm{K}: 0,80$ mmolc dm$^{-3}$; Ca: 2,0 mmolc dm${ }^{-3} ; \mathrm{Mg}: 3,0$ mmolc dm ${ }^{-3}$; CTC: 26,0 mmolc dm ${ }^{-3}$ e V (\%): 23.

No experimento foi utilizado o delineamento em blocos casualizados em esquema fatorial $2 \times 2 \times 2$, com três repetições, totalizando 24 parcelas experimentais. O primeiro fator foi o milho transgênico utilizado (Yeld Gard e Feroz Víptera); o segundo, o espaçamento entre fileiras (0,6 e 0,8 m); e o terceiro, o espaçamento entre plantas (0,2 e 0,3 m). Cada parcela experimental constava com quatro fileiras de milho com quatro metros de comprimento, com área variável em função dos espaçamentos. 
A parcela útil foi composta pelas duas fileiras centrais, com dois metros de comprimento cada, sendo as duas fileiras laterais, e o primeiro e o último metro das fileiras da parcela considerados como bordadura, procurando reduzir a influência das parcelas posicionadas próximas.

As cultivares de milho utilizadas foram a cultivar da Monsanto DKC6667YG, com tecnologia Yield Gard e o híbrido transgênico da Syngenta, o Feroz que possui tecnologia Viptera, TG, TL/ TGTG que conferem resistência às principais lagartas que atacam a cultura.

A dose de adubação recomendada foi obtida com base na análise de solo conforme recomendação da Embrapa para a cultura do milho (COELHO et al., 2012). Dessa forma, foram utilizados na adubação de fundação $100 \mathrm{~kg} \mathrm{ha}^{-1}$ de sulfato de amônio (20 kg ha-1 de N), $670 \mathrm{~kg}$ ha-1 de superfosfato simples (120 kg ha-1 de $\mathrm{P}_{2} \mathrm{O}_{5}$ ) e $133 \mathrm{~kg} \mathrm{ha}^{-1}$ de cloreto de potássio ( $80 \mathrm{~kg} \mathrm{ha}^{-1}$ de $\mathrm{K}_{2} \mathrm{O}$ ), sendo que essa dose de potássio é a metade do recomendado, com a outra metade sendo aplicada junto com a primeira adubação de cobertura nitrogenada.

A adubação nitrogenada em cobertura foi realizada em todas as parcelas, aplicando-se 450 $\mathrm{kg} \mathrm{ha}^{-1}$ de sulfato de amônio (90 kg ha ${ }^{-1}$ de N), sendo parcelada em duas aplicações, a primeira entre V3 e V4 e a segunda entre V6 e V7, em função de o solo ter textura arenosa.

A semeadura foi realizada por uma semeadora manual da knapik com distribuição de sementes por discos horizontais, sendo regulada para depositar as sementes a cada 0,2 ou 0,3 m conforme os tratamentos.

O sistema de irrigação utilizado foi de microaspersão, com vazão média por aspersor de 80 L. $h^{-1}$, em que cada aspersor foi posicionado a 4 metros de distância dentro da linha de irrigação, e cada linha foi posicionada a 3,2 m de distância, proporcionando uma lâmina de irrigação de aproximadamente $6,67 \mathrm{~mm} . \mathrm{h}^{-1}$, com o turno de rega sendo efetuado diariamente.

Foram efetuadas duas capinas manuais para controle de plantas daninhas, sendo realizadas dias antes da adubação de cobertura, evitando-se competição pelos nutrientes entre o milho e as plantas daninhas.

A colheita das parcelas experimentais ocorreu aos 90 dias após a semeadura, quando as plantas estavam entre 30 e 35\% de matéria seca, condição ideal para o processo de ensilagem.

As variáveis analisadas foram altura da planta e de inserção da primeira espiga, comprimento da espiga, diâmetro da espiga, massa das espigas e das plantas e a produtividade de massa das espigas, de plantas e total por hectare.

A altura da planta e da inserção da primeira espiga foram medidas entre o nível do solo e a inserção da folha bandeira e até a base de inserção da primeira espiga, respectivamente. Foram medidas dez plantas por parcela.

Nas plantas colhidas na parcela útil, foram selecionadas ao acaso dez espigas por parcela, para a determinação do comprimento e do diâmetro da espiga, com o auxílio de uma fita métrica e de paquímetro, respectivamente. Ressalta-se que essas medidas foram realizadas para a espiga com e sem a palha.

Foi realizada a pesagem das plantas, separadas em: folhas e colmos; espigas com e sem palha. Isso forneceu um dado médio por parcela na unidade de gramas por espiga e gramas por planta de milho (Folhas e Colmo).

Com os dados de massa verde de espigas e número de espigas por hectare, foi determinada a massa verde de espigas por hectare $\left(\mathrm{kg} \mathrm{ha}^{-1}\right)$, com e sem palha. E com a massa por planta (Folhas e Colmo) e o número de plantas por hectare, determinou-se a massa de plantas por hectare. 
Para comparar e interpretar os resultados, os dados foram submetidos à análise de variância pelo teste $\mathrm{F}$, e as médias comparadas pelo teste de Tukey a $5 \%$ de probabilidade. Foi utilizado o programa estatístico Sisvar 5.3 (FERREIRA, 2008).

\section{RESULTADOS E DISCUSSÃO}

Verifica-se na Tabela 1 que o coeficiente de variação, de acordo com Pimentel Gomes (2009), foi baixo para todas as variáveis analisadas, demonstrando bom controle do acaso e permitindo discussões mais bem fundamentadas.

Tabela 1 - Síntese da análise de variância e do teste de médias para a altura de plantas (AP), a altura de inserção da primeira espiga (AE) e o número de espigas por planta (NEP), UFCA, Crato, CE, 2015

\begin{tabular}{|c|c|c|c|}
\hline \multirow{2}{*}{ FATORES } & AP & $\mathrm{AE}$ & NEP \\
\hline & \multicolumn{2}{|c|}{ 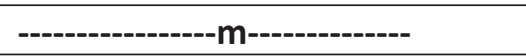 } & \multirow[t]{2}{*}{ Unidade } \\
\hline Milho Transgênico (T) & & & \\
\hline Monsanto - Yeld Gard & $1,76 \mathrm{a}$ & 0,99 a & 1,04 \\
\hline Syngenta - Feroz & $1,75 \mathrm{a}$ & $1,01 \mathrm{a}$ & 1,13 \\
\hline \multicolumn{4}{|l|}{ Espaçamento Fileiras (EF) } \\
\hline $0,6 \mathrm{~m}$ & $1,77 \mathrm{a}$ & $1,00 \mathrm{a}$ & $1,06 \mathrm{a}$ \\
\hline $0,8 \mathrm{~m}$ & $1,74 \mathrm{a}$ & $1,00 \mathrm{a}$ & $1,12 \mathrm{a}$ \\
\hline \multicolumn{4}{|l|}{ Espaçamento Plantas (EP) } \\
\hline $0,2 \mathrm{~m}$ & $1,76 \mathrm{a}$ & $1,01 \mathrm{a}$ & 1,14 \\
\hline $0,3 \mathrm{~m}$ & $1,74 \mathrm{a}$ & $0,99 a$ & 1,03 \\
\hline \multicolumn{4}{|l|}{ TESTE F } \\
\hline $\mathrm{T}$ & 0,01 Ns & $0,11^{\mathrm{NS}}$ & $6,37 *$ \\
\hline EF & $0,45^{\mathrm{NS}}$ & $0,01^{\mathrm{NS}}$ & $2,56^{\mathrm{NS}}$ \\
\hline EP & $0,12^{\mathrm{NS}}$ & $0,38^{\mathrm{NS}}$ & $8,89 * *$ \\
\hline$T^{*} \mathrm{EF}$ & 0,01 Ns & $0,01^{\text {NS }}$ & $1,31^{\mathrm{NS}}$ \\
\hline$T * E P$ & 0,02 NS & $0,09^{\mathrm{NS}}$ & $6,37 *$ \\
\hline$E F^{*} E P$ & $0,74^{\mathrm{NS}}$ & $2,62^{\mathrm{NS}}$ & $0,47^{\mathrm{NS}}$ \\
\hline$T^{*} \mathrm{EF} * \mathrm{EP}$ & 2,18 Ns & $3,46^{\mathrm{NS}}$ & $4,26^{\mathrm{NS}}$ \\
\hline CV\% & 7,44 & 10,23 & 8,18 \\
\hline
\end{tabular}

Médias seguidas pela mesma letra na coluna, não diferem entre si pelo teste de Tukey a $5 \%$ de probabilidade.**: significativo ( $P<0,01)$; *: significativo ( $P<0,05)$; NS: não significativo; $C V \%$ : coeficiente de variação.

Na Tabela 1, para a altura das plantas e de inserção da primeira espiga, não houve significância $(p>0,05)$ para todos os fatores estudados. Observa-se que todos os fatores obtiveram altura de plantas média próximo a 1,75 m e de inserção da primeira espiga de 1,00 m.

Uate et al. (2014), em Minas Gerais, encontraram resultados de altura das plantas menores do que as encontradas neste trabalho (1,54 $\mathrm{m}$ de altura), assim como a altura das espigas que ficaram em torno de 0,8 m. Já os resultados obtidos por Silva et al. (2010) no estado do Paraná, apresentanram a altura média das plantas de 2,38 m, superando as obtidas neste trabalho. Apesar de plantas mais altas, a altura de inserção da espiga foi semelhante $(1,01 \mathrm{~m})$, assemelhando-se aos encontrados por Paziani et al. (2009), em São Paulo, e por Santos et al. (2010), em Pernambuco. 
Observa-se, também, que ocorreu interação significativa apenas para o número de espigas por planta entre os fatores milho transgênico e espaçamento entre plantas, fato que evidencia a necessidade da realização do desdobramento da interação (Tabela 2).

Tabela 2 - Interação entre os fatores: transgênico e espaçamento entre plantas, para a variável número de espigas por planta, UFCA, Crato, CE, 2015

\begin{tabular}{ccc}
\hline \multirow{2}{*}{ TRANSGÊNICO } & \multicolumn{2}{c}{ ESPAÇAMENTO ENTRE PLANTAS } \\
\cline { 2 - 3 } & $\mathbf{0 , 2} \mathbf{~}$ & $\mathbf{0 , 3} \mathbf{~}$ \\
\hline Monsanto - Yeld Gard & $1,05 \mathrm{bA}$ & $1,03 \mathrm{aA}$ \\
Syngenta - Feroz & $1,23 \mathrm{aA}$ & $1,03 \mathrm{aB}$ \\
\hline
\end{tabular}

Médias seguidas pela mesma letra minúscula nas colunas e maiúscula nas linhas, não diferem estatisticamente entre si segundo o teste de Tukey a $5 \%$ de probabilidade.

O desdobramento da interação para o número de espigas por planta (Tabela 2) evidencia que a cultivar da Monsanto se comportou diferente da Syngenta, no espaçamento de 0,2 m entre plantas, apresentando menor número de espigas por planta, já quando o espaçamento foi de $0,3 \mathrm{~m}$, as duas cultivares produziram valores iguais.

Com relação ao espaçamento entre as plantas, a cultivar Monsanto não sofreu influência significativa, enquanto o menor espaçamento proporcionou maior número de espigas por planta para a cultivar Syngenta. Esses dados discordam dos obtidos por Araujo et al. (2016), que, trabalhando com espaçamento reduzido para a cultura do milho, com esses mesmos cultivares, observaram produção de 0,97 e 0,96 espigas por planta para o transgênico Yeld Gard e Feroz Viptera, respectivamente.

$\mathrm{Na}$ Tabela 3, verifica-se que ocorreram baixos valores de coeficiente de variação para todas as variáveis, segundo a classificação de Pimentel Gomes (2009), exceto o diâmetro da espiga sem palha que obteve valor médio. Ainda se nota que não ocorreram interações significativas entre os fatores para todas as variáveis analisadas, sendo possível a discussão direta por meio dos dados médios para os níveis de cada fator analisado.

Observa-se que os fatores milho transgênico e o espaçamento entre fileiras de milho não obtiveram resultados significativos para todas as variáveis analisadas, obtendo valores semelhantes (Tabela 3). Já para o espaçamento entre plantas, o de 0,3 m proporcionou maior comprimento da espiga com palha, com as demais variáveis sendo iguais estatisticamente $(p>0,05)$.

O diâmetro das espigas foi semelhante aos encontrados por Silva et al. (2010), em torno de $5 \mathrm{~cm}$, entretanto o comprimento foi superior, com média de espigas de $31,1 \mathrm{~cm}$, diferente das espigas deste trabalho que obteve média de $23,5 \mathrm{~cm}$.

Gonçalves, Gondim Neto e Diógenes (2012) avaliaram o milho em sistema de plantio convencional, na Embrapa Amazônia, em solo com boa fertilidade natural, utilizando espaçamento entre fileiras de 0,9 m, e duas variedades (Saracura e Sol da manhã) e o híbrido BRS 1030 de milho, obtiveram espigas sem palha com diâmetro médio de 4,1 cm e comprimento médio de $15,51 \mathrm{~cm}$, valores próximos aos desta pesquisa. Esses resultados demonstram bom desenvolvimento desses materiais transgênicos na região em estudo, uma vez que o solo desta pesquisa é considerado de baixa fertilidade natural. 
Tabela 3 - Síntese da análise de variância e do teste de médias para o comprimento da espiga com palha (CECP), o diâmetro da espiga com palha (DECP), o comprimento da espiga sem palha (CESP), e o diâmetro da espiga sem palha (DESP), UFCA, Crato, CE, 2015

\begin{tabular}{|c|c|c|c|c|}
\hline \multirow{2}{*}{ Fatores } & CECP & DECP & CESP & DESP \\
\hline & \multicolumn{4}{|c|}{ |-------------------------------'Cm------------------------------- } \\
\hline \multicolumn{5}{|l|}{ Milho Transgênico (T) } \\
\hline Monsanto - Yeld Gard & $23,1 \mathrm{a}$ & $5,1 \mathrm{a}$ & $15,6 \mathrm{a}$ & 4,6 a \\
\hline Syngenta - Feroz & $22,8 \mathrm{a}$ & $5,0 \mathrm{a}$ & $15,4 \mathrm{a}$ & $4,2 \mathrm{a}$ \\
\hline \multicolumn{5}{|l|}{ Espaçamento Fileiras (EF) } \\
\hline $0,6 \mathrm{~m}$ & $23,2 \mathrm{a}$ & $5,0 \mathrm{a}$ & $15,2 \mathrm{a}$ & 4,6 a \\
\hline $0,8 \mathrm{~m}$ & $22,8 \mathrm{a}$ & $5,1 \mathrm{a}$ & $15,8 \mathrm{a}$ & $4,1 \mathrm{a}$ \\
\hline \multicolumn{5}{|l|}{ Espaçamento plantas (EP) } \\
\hline $0,2 \mathrm{~m}$ & $22,4 b$ & 4,9 a & $15,0 \mathrm{a}$ & $4,1 \mathrm{a}$ \\
\hline $0,3 \mathrm{~m}$ & $23,5 \mathrm{a}$ & $5,1 \mathrm{a}$ & $15,9 \mathrm{a}$ & $4,6 \mathrm{a}$ \\
\hline \multicolumn{5}{|l|}{ TESTE F } \\
\hline $\mathrm{T}$ & $0,78^{N S}$ & $0,94^{\text {NS }}$ & $0,26^{\text {NS }}$ & $1,04^{\mathrm{NS}}$ \\
\hline $\mathrm{EF}$ & $1,14^{\mathrm{NS}}$ & $1,51^{\mathrm{NS}}$ & $1,83^{\mathrm{NS}}$ & $1,65^{\text {NS }}$ \\
\hline EP & $7,70 *$ & 3,88 NS & 4,23 NS & $1,54^{\mathrm{NS}}$ \\
\hline $\mathrm{T} * \mathrm{EF}$ & $1,01^{\mathrm{NS}}$ & $0,02^{N S}$ & $4,44^{\mathrm{NS}}$ & $2,28^{\mathrm{NS}}$ \\
\hline$T^{*} E P$ & $0,42^{\text {NS }}$ & $2,62^{\text {NS }}$ & $4,78^{\text {NS }}$ & $1,95^{\mathrm{NS}}$ \\
\hline$E F * E P$ & $0,15^{\text {NS }}$ & $0,04^{\mathrm{NS}}$ & $1,81^{\text {NS }}$ & $1,01^{\mathrm{NS}}$ \\
\hline$T^{*} E F * E P$ & 4,09 NS & $3,05^{\text {NS }}$ & $2,46^{\mathrm{NS}}$ & $0,65^{\mathrm{NS}}$ \\
\hline CV\% & 4,09 & 4,39 & 6,76 & 20,37 \\
\hline
\end{tabular}

Médias seguidas pela mesma letra na coluna, não diferem entre si pelo teste de Tukey a $5 \%$ de probabilidade.**: significativo $(P<0,01)$; *: significativo $(P<0,05)$; NS: não significativo; $C V \%$ : coeficiente de variação.

Tabela 4 - Síntese da análise de variância e do teste de médias para a massa da espiga com palha (MECP), a massa da espiga sem palha (MESP) e a massa da palha da espiga (MPE), UFCA, Crato, CE, 2015

\begin{tabular}{|c|c|c|c|}
\hline \multirow{2}{*}{ FATORES } & MECP & MESP & MPE \\
\hline & \multicolumn{3}{|c|}{ 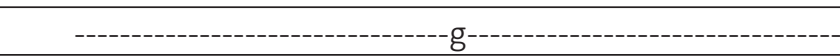 } \\
\hline \multicolumn{4}{|l|}{ Milho Transgênico ( $\mathrm{T}$ ) } \\
\hline Monsanto - Yeld Gard & $250 a$ & $202 \mathrm{a}$ & $48 \mathrm{a}$ \\
\hline Syngenta - Feroz & $244 \mathrm{a}$ & 203 a & $41 \mathrm{a}$ \\
\hline \multicolumn{4}{|l|}{ Espaçamento Fileiras (EF) } \\
\hline $0,6 \mathrm{~m}$ & $241 \mathrm{a}$ & $202 \mathrm{a}$ & 39 a \\
\hline $0,8 \mathrm{~m}$ & $253 a$ & $203 a$ & $50 \mathrm{a}$ \\
\hline \multicolumn{4}{|l|}{ Espaçamento plantas (EP) } \\
\hline $0,2 \mathrm{~m}$ & $229 \mathrm{~b}$ & 193 a & $36 b$ \\
\hline $0,3 \mathrm{~m}$ & $264 a$ & $212 \mathrm{a}$ & $52 \mathrm{a}$ \\
\hline \multicolumn{4}{|l|}{ TESTE F } \\
\hline $\mathrm{T}$ & $0,26^{\text {NS }}$ & $0,01^{\mathrm{NS}}$ & 0,98 NS \\
\hline EF & $0,94^{\mathrm{NS}}$ & $0,01^{\mathrm{NS}}$ & $2,76^{\mathrm{NS}}$ \\
\hline EP & 7,84 * & 3,23 NS & $5,69 *$ \\
\hline $\mathrm{T} * \mathrm{EF}$ & $0,81^{\text {NS }}$ & $1,47^{\mathrm{NS}}$ & $0,05^{\mathrm{NS}}$ \\
\hline$T^{*} E P$ & 3,23 NS & $4,39^{\mathrm{NS}}$ & 0,01 NS \\
\hline$E F^{*} E P$ & $0,11^{\mathrm{NS}}$ & $0,01^{\mathrm{NS}}$ & 0,41 NS \\
\hline$T^{*} E F * E P$ & $3,91^{\text {NS }}$ & $1,98^{\mathrm{NS}}$ & $2,15^{\mathrm{NS}}$ \\
\hline CV\% & 12,39 & 12,72 & 37,23 \\
\hline
\end{tabular}

Médias seguidas pela mesma letra na coluna, não diferem entre si pelo teste de Tukey a 5\% de probabilidade.**: 
significativo ( $P<0,01)$; *: significativo ( $P<0,05)$; NS: não significativo; CV\%: coeficiente de variação.

Na tabela 4, nota-se que o coeficiente de variação para as variáveis foram médios e muito alto, segundo a classificação proposta por Pimentel Gomes (2009) para experimentos em campo, com tais variações sendo normais em virtude de vários fatores não controlados. Observa-se, ainda, que não ocorreu interação significativa entre os fatores.

Na Tabela 5, nota-se que o coeficiente de variação para a MCP foi alto e, para a MFP e a MP, tiveram valor médio, de acordo com a classificação proposta por Pimentel Gomes (2009). Observa-se, ainda, que não ocorreu interação significativa entre os fatores para todas as variáveis analisadas.

Os milhos transgênicos não apresentaram diferenças significativas $(p>0,05)$ para todas as variáveis analisadas (Tabela 5). Com relação aos espaçamentos, nota-se que apenas o espaçamento entre plantas obteve diferença para a massa de folhas por planta e a massa por planta, com maiores valores observados com a maior distância estudada (0,3 m).

Tabela 5 - Síntese da análise de variância e do teste de médias para a massa de colmo por planta (MCP), a massa de folhas por planta (MFP) e a massa por planta (MP), a massa verde de colmos (MVC), a massa verde de folhas (MVF) e a massa verde de plantas (MVP), UFCA, Crato, CE, 2015

\begin{tabular}{|c|c|c|c|c|c|c|}
\hline \multirow{2}{*}{ Fatores } & MCP & MFP & MP & MVC & MVF & MVP \\
\hline & \multicolumn{3}{|c|}{ 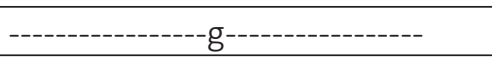 } & \multicolumn{3}{|c|}{ 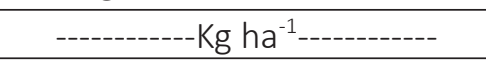 } \\
\hline \multicolumn{7}{|l|}{ Milho Transgênico (T) } \\
\hline Monsanto - Yeld Gard & $84,4 \mathrm{a}$ & $200,7 a$ & $285,1 \mathrm{a}$ & $12148 \mathrm{a}$ & 5118 a & $17266 \mathrm{a}$ \\
\hline Syngenta - Feroz & 85,3 a & $201,0 \mathrm{a}$ & $286,3 \mathrm{a}$ & $11880 \mathrm{a}$ & 5066 a & $16946 \mathrm{a}$ \\
\hline \multicolumn{7}{|l|}{ Espaçamento Fileiras (EF) } \\
\hline $0,6 \mathrm{~m}$ & $85,5 \mathrm{a}$ & $208,5 a$ & $294,0 \mathrm{a}$ & 14158 a & 5851 a & $20009 a$ \\
\hline $0,8 \mathrm{~m}$ & $84,2 \mathrm{a}$ & 193,2 a & $277,4 a$ & $9870 \mathrm{~b}$ & $4333 \mathrm{~b}$ & $14203 \mathrm{~b}$ \\
\hline \multicolumn{7}{|l|}{ Espaçamento plantas (EP) } \\
\hline $0,2 \mathrm{~m}$ & 79,5 a & $180,5 b$ & $260,0 \mathrm{~b}$ & 13215 a & 5798 a & 19013 a \\
\hline $0,3 \mathrm{~m}$ & $90,2 \mathrm{a}$ & $221,2 \mathrm{a}$ & $311,4 \mathrm{a}$ & $10813 b$ & $4386 b$ & $15199 \mathrm{~b}$ \\
\hline \multicolumn{7}{|l|}{ TESTE $F$} \\
\hline$T$ & 0,01 NS & $0,01^{\text {NS }}$ & $0,00^{N S}$ & $0,07^{\mathrm{NS}}$ & $0,01^{\text {NS }}$ & $0,06^{\mathrm{NS}}$ \\
\hline EF & $0,02^{N S}$ & 1,03 Ns & $0,64^{\mathrm{NS}}$ & $18,54 * *$ & $7,44 *$ & $18,48 * *$ \\
\hline EP & $1,27^{\mathrm{NS}}$ & $7,34 *$ & $6,19 *$ & $5,82 *$ & $6,44 *$ & $8,41 *$ \\
\hline$T^{*} E F$ & 0,02 NS & 0,23 Ns & $0,08^{N S}$ & $0,67^{\mathrm{NS}}$ & $0,01^{\text {NS }}$ & $0,32^{\text {NS }}$ \\
\hline$T^{*} E P$ & 1,01 NS & $0,85^{\text {NS }}$ & $1,31^{\mathrm{NS}}$ & $1,23^{\mathrm{NS}}$ & $1,07^{\mathrm{NS}}$ & 1,63 NS \\
\hline$E F^{*} E P$ & 0,01 NS & $0,09^{\text {NS }}$ & $0,07^{\mathrm{NS}}$ & $0,06^{\mathrm{NS}}$ & $0,08^{\text {NS }}$ & $0,09^{N S}$ \\
\hline$T^{*} \mathrm{EF} * \mathrm{EP}$ & $0,00^{N S}$ & $3,75^{\mathrm{NS}}$ & $1,94^{\mathrm{NS}}$ & $3,95^{\mathrm{NS}}$ & $0,01^{\text {NS }}$ & $2,37^{\mathrm{NS}}$ \\
\hline CV\% & 27,31 & 18,35 & 17,72 & 20,30 & 26,77 & 18,84 \\
\hline
\end{tabular}

Médias seguidas pela mesma letra minúscula na coluna, não diferem entre si pelo teste de Tukey a $5 \%$ de probabilidade. ${ }^{* *}$ : significativo $(\mathrm{P}<0,01)$; *: significativo $(\mathrm{P}<0,05)$; NS: não significativo; $\mathrm{CV} \%$ : coeficiente de variação.

Na Tabela 5, notou-se que a produtividade por hectare de massa verde de colmos, folhas e da planta inteira, para as cultivares, foram semelhantes ( $p>0,05)$, enquanto que para os espaçamentos, foi observado diferença significativa a $1 \%$ para todas as variáveis, com os espaçamentos reduzidos proporcionando maiores valores para todas as variáveis.

Nota-se que o espaçamento reduzido entre plantas proporcionou menores valores de 
massa verde por planta (Tabela 5), porém, em função do maior número de plantas e melhor aproveitamento da área, a produtividade de massa verde por hectare foi $25 \%$ superior para 0,2 m entre plantas em relação a 0,3 m (Tabela 5).

Esses resultados evidenciam que o aumento na distância entre as plantas promove melhor aproveitamento dos recursos naturais pelas plantas de forma individual, proporcionando maiores produções de massa por planta. Porém a utilização de espaçamentos reduzidos tem entre suas principais caractetísticas o melhor controle de plantas invasoras, maior aproveitamento de luz, água e de nutrientes, melhor distribuição das plantas na área e controle de erosão (BALBINOT; FLECK, 2005; ALVAREZ, PINHO; BORGES, 2006).

Nakano Neto e Mello (2010) obtiveram uma produção de massa verde de colmo de $24688 \mathrm{~kg}$ ha-1 ${ }^{-1}$ superior à maior produção conseguida neste trabalho (14158 kg ha-1) além da maior produção de colmo, a produção de folhas também foi maior, chegando a $13359 \mathrm{~kg} \mathrm{ha}^{-1}$. Esses melhores resultados alcançados por esses autores podem ser em função da melhor fertilidade natural do solo e do período de execução da pesquisa, que foi durante o verão (dezembro a março), época na qual o comprimento do dia e as temperaturas são maiores no estado de São Paulo, fato que favorece o desenvolvimento das plantas, com a máxima expressão do potencial genético (COELHO et al., 2012).

O coeficiente de variação da MVPE (Tabela 6) foi alto se destacando dos demais que ficaram abaixo de 20\%. Os milhos transgênicos obtiveram resultados semelhantes para todas as variáveis, e os espaçamentos entre plantas e fileiras foram iguais estatisticamente somente para a palha da espiga, com as demais variáveis tendo diferenças significativas.

Para o espaçamento entre plantas e entre fileiras, foram observados maiores valores para os espaçamentos reduzidos de 0,2 e 0,6 m, respectivamente. Rosa et al. (2004), em Argissolo Vermelho amarelo, textura arenosa e de baixa fertilidade (similar ao deste trabalho), em Santa Maria- RS, obtiveram resultados de produções próximas aos obtidos neste trabalho, para o milho híbrido AG-5011 que produziu $38.144 \mathrm{~kg} \mathrm{ha}^{-1}$ de massa verde, já os outros dois híbridos avaliados XL-344 e C-806 foram inferiores, apresentando 26.654 e $29.855 \mathrm{~kg} \mathrm{ha}^{-1}$, respectivamente.

Resultados semelhantes foram obtidos por Santos et al. (2010), em Latossolo Vermelho Amarelo, textura arenosa e de baixa fertilidade, no munícipio de Petrolina-PE, analisando seis variedades, encontraram produção média de MVT de $33.800 \mathrm{~kg} \mathrm{ha}^{-1}$.

Observa-se, que os trabalhos de Rosa et al. (2004) e de Santos et al. (2010), obtiveram resultados semelhantes aos desta pesquisa, uma vez que foram realizados em solos de textura arenosa e de baixa fertilidade natural, com as diferenças climáticas entre as regiões Sul e Nordeste do país tendo pouca influência, uma vez que as pesquisas no Nordeste foram conduzidas em regime irrigado, suprindo adequadamente a demanda hídrica da cultura.

Já quando os dados são confrontados com trabalhos realizados em solos com melhor fertilidade e maior CTC (argilosos), as produtividades de massa verde foram menores. Como os obtidos por Lupatini et al. (2004), em Latossolo Roxo, que observaram média de $45.000 \mathrm{~kg} \mathrm{ha}^{-1}$, ao avaliarem 15 híbridos de milho no sudoeste paranaense, valores esses superados por Paziani et al. (2009) que obtiveram uma média de $50.470 \mathrm{~kg} \mathrm{ha}^{-1}$, no estado de São Paulo. 
Tabela 6 - Síntese da análise de variância e do teste de médias para a massa verde da espiga com palha (MVECP), a massa verde da espiga sem palha (MVESP), a massa verde da palha da espiga (MVPE) e a massa verde total (MVT), UFCA, Crato, CE, 2015

\begin{tabular}{|c|c|c|c|c|}
\hline \multirow{2}{*}{ Fatores } & MVECP & MVESP & MVPE & MVT \\
\hline & \multicolumn{4}{|c|}{ 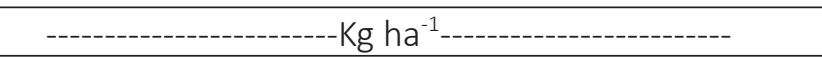 } \\
\hline \multicolumn{5}{|l|}{ Milho Transgênico (T) } \\
\hline Monsanto - Yeld Gard & 15708 a & 12827 a & $2881 \mathrm{a}$ & $32974 \mathrm{a}$ \\
\hline Syngenta - Feroz & 16493 a & 13797 a & $2696 \mathrm{a}$ & $33440 \mathrm{a}$ \\
\hline \multicolumn{5}{|l|}{ Espaçamento Fileiras (EF) } \\
\hline $0,6 \mathrm{~m}$ & 17616 a & 14838 a & $2778 a$ & $37625 a$ \\
\hline $0,8 \mathrm{~m}$ & $14586 \mathrm{~b}$ & 11786 b & $2800 \mathrm{a}$ & $28789 \mathrm{~b}$ \\
\hline \multicolumn{5}{|l|}{ Espaçamento plantas (EP) } \\
\hline $0,2 \mathrm{~m}$ & 18976 a & 15966 a & 3010 a & 37989 a \\
\hline $0,3 \mathrm{~m}$ & $13226 \mathrm{~b}$ & $10658 \mathrm{~b}$ & $2568 \mathrm{a}$ & $28425 b$ \\
\hline \multicolumn{5}{|l|}{ TESTE F } \\
\hline $\mathrm{T}$ & $0,38^{\mathrm{NS}}$ & $0,96^{\mathrm{NS}}$ & $0,13^{\mathrm{NS}}$ & $0,04^{\mathrm{NS}}$ \\
\hline EF & $5,67^{*}$ & $9,47 * *$ & $0,02^{\text {NS }}$ & $14,17^{* *}$ \\
\hline EP & $20,44 * *$ & $28,64 * *$ & $0,75^{\mathrm{NS}}$ & $16,61 * *$ \\
\hline$T^{*} \mathrm{EF}$ & $0,07^{\mathrm{NS}}$ & 0,01 NS & $0,67^{\mathrm{NS}}$ & $0,21^{\mathrm{NS}}$ \\
\hline$T^{*} E P$ & $0,06^{\mathrm{NS}}$ & $0,14^{\mathrm{NS}}$ & $0,01^{\mathrm{NS}}$ & $0,73^{N S}$ \\
\hline$E F^{*} E P$ & $0,14^{\mathrm{NS}}$ & $0,16^{\mathrm{NS}}$ & $0,03^{N S}$ & $0,14^{\mathrm{NS}}$ \\
\hline$T^{*} E F^{*} E P$ & $4,45^{\mathrm{NS}}$ & $3,36^{\mathrm{NS}}$ & $2,87^{\mathrm{NS}}$ & 4,03 NS \\
\hline CV\% & 19,35 & 18,25 & 44,90 & 17,31 \\
\hline
\end{tabular}

Médias seguidas pela mesma letra minúscula na coluna, não diferem entre si pelo teste de Tukey a $5 \%$ de probabilidade. ${ }^{* *}$ : significativo $(\mathrm{P}<0,01)$; *: significativo $(\mathrm{P}<0,05)$; NS: não significativo; $\mathrm{CV} \%$ : coeficiente de variação.

\section{CONCLUSÕES}

Os materiais de milho transgênico proporcionaram valores similares para todas as variáveis analisadas.

O espaçamento reduzido entre fileiras proporcionou massa por planta igual ao maior espaçamento, com maior produtividade de massa verde total.

O maior espaçamento entre plantas teve maior massa por planta, porém com menor massa verde total.

Para a região do Cariri cearense, os espaçamentos menores são mais indicados para a produção de forragem, podendo ser utilizado o milho transgênico da Monsanto Yeld Gard ou o da Syngenta Feroz Víptera.

\section{REFERÊNCIAS}

ALVAREZ, C. G. D.; PINHO, R. G.; BORGES, I. D. Avaliação de características agronômicas e de produção de forragens e grãos de milho em diferentes densidades de semeadurae espaçamentos entre linhas. Ciência e Agrotecnologia, Lavras, MG, v. 30, n. 3, p.402-408, maio/jun. 2006.

ALVES, B. M.; CARGNELUTTI FILHO, A.; TOEBE, C. B. M.; SILVA, L. P. Divergência genética de milho transgênico em relação à produtividade de grãos e da qualidade nutricional. Ciência Rural, Santa Maria, RS, v. 45, n. 5, p. 884-891, maio 2015.

ARAUJO, L. S.; SILVA, L. G. B.; SILVEIRA, P. M.; RODRIGUES, F.; LIMA, M. L. P.; CUNHA, P. C. R. Desempenho agronômico de híbrido de milho na região sudeste de Goiás. Revista Agro@mbiente Online, v. 10, p. 334-342, 2016. 
BALBINOT, A. A.; FLECK, N. G. Benefício e limitações da redução do espaçamento entre linhas. Revista Plantio Direto, Passo Fundo, RS, v. 5, p. 37-41, 2005.

COELHO, Antonio Marcos; FRANÇA, Gonçalo Evangelista de; PITTA, Gilson Villaça Exel; ALVES, Vera Maria Carvalho; HERNANI, Luiz Carlos. Nutrição e adubação do milho. EMBRAPA. Cultivo do milho, out. 2010. Disponível em: <http://www.cnpms.embrapa.br/publicacoes/milho_8_ed/feraduba.htm>. Acesso em: 15 maio 2015.

CRUZ, J. C.; PEREIRA FILHO, I. A.; OLIVEIRA, M. F. Arranjo espacial de plantas em diferentes cultivares de milho. Embrapa Milho e Sorgo. Sete Lagoas, 2000. Disponível em: <https://www.alice.cnptia.embrapa. br/alice/bitstream/doc/490168/1/Arranjoespacial.pdf>. Acesso em: 20 maio 2015.

FERREIRA, D. F. SISVAR: um programa para análises e ensino de estatística. Revista Symposium, Lavras, MG, v. 6, p. 36-41, 2008.

FERRARI JUNIOR, E.; POSSENTI, R. A.; LIMA, M. L. P.; NOGUEIRA, J. R.; ANDRADE, J. B. Características, composição química e qualidade de silagens de oito cultivares de milho. Boletim de Indústria Animal, v. 62, n. 1, p. 19-27, 2005.

FUNDAÇÃO CEARENSE DE METEOROLOGIA E RECURSOS HÍDRICOS (FUNCEME). Levantamento de reconhecimento de média intensidade dos solos da Mesoregião do Sul Cearense. Fortaleza, CE: FUNCEME, 2012. 98 p.

GONÇALVES, J. R. P.; GONDIM NETO, M. A.; DIÓGENES, H. C. Desenvolvimento e produtividade de genótipos de milho sob diferentes manejos de solo em várzea amazônica. In: REUNIÃO BRASILEIRA DE FERTILIDADE DO SOLO E NUTRIÇÃO DE PLANTAS, 30.; REUNIÃO BRASILEIRA SOBRE MICORRIZAS, 14.; SIMPÓSIO BRASILEIRO MICROBILOGIA DO SOLO, 12.; REUNIÃO BRASILEIRA DE BIOLOGIA DO SOLO, 9.; SIMPÓSIO SOBRE SELÊNIO NO BRASIL, 1., 2012, Macéio. FERTBIO 2012: "A responsabilidade socioambiental da pesquisa agrícola". Anais... Maceió, AL: Sociedade Brasileira de Ciência do Solo; Centro de Ciências Agrárias da Universidade Federal de Alagoas, 2012. 1 CR-ROM. Disponível em: <https://ainfo.cnptia.embrapa.br/digital/bitstream/ item/77274/1/2012AA58.pdf>. Acesso em: 20 maio 2015.

GUARESCHI, R. F.; GAZOLLA, P. R.; PERIN, A.; ROCHA, A. C. Produção de massa de milho silagem em função do arranjo populacional e adubação. Revista Ciência Agronômica, Fortaleza, CE, v. 39, n. 3, p. 468-475, 2008.

LUPATINI, G. C.; MACCARI, M.; ZANETTE, S.; PIACENTINI, E.; NEUMANN, M. Avaliação do desempenho agronômico de híbridos de milho (Zea mays, L.) para produção de silagem. Revista Brasileira de Milho e Sorgo, v. 3, n. 2, p. 193-203, 2004.

MENDES, M. C.; VON PINHO, R. G.; LIMA, T. G. Associação entre características e desempenho de híbridos de milho para produção de forragem. In: CONGRESSO NACIONAL DE MILHO E SORGO, 26., 2006, Belo Horizonte. Anais... Belo Horizonte: ABMS, 2006. p.203.

NAKANO NETO, M.; MELLO, S. P. Podução de silagens de milho (Zea Mays, L.) com diferentes adubações. Nucleus, v. 7, n. 2, p. 155-164, 2010.

PAZIANI, S. D. F.; DUARTE, A. P.; NUSSIO, L. G.; GALLO, P. B.; BITTAR, C. M. M.; ZOPOLLATTO, M.; RECO, P. C. Características agronômicas e bromatológicas de híbridos de milho para produção de silagem. Revista Brasileira de Zootecnia, Viçosa, MG, v. 38, n. 3, p. 411-417, mar. 2009.

PIMENTEL GOMES, F. Curso de estatística experimental. 15. ed. Piracicaba, SP: FEALQ, 2009. 451p.

ROSA, J. R. P.; SILVA, J. H. S.; RESTLE, J.; PASCOAL, L. L.; BRONDANI, I. L.; ALVES FILHO, D. C.; FREITAS, A. K. Avaliação do comportamento agronômico da planta e valor nutritivo da silagem de diferentes híbridos de milho (Zea mays, L.). Revista Brasileira de Zootecnia, v. 33, n. 2, p. 302-312, 2004.

SANGOI, L. Understanding plant density effects on maize growth and development: un important issue to maximize grain yield. Ciência Rural, Santa Maria, RS, v. 31, n. 1, p. 159-168, jan./fev. 2000.

SANTOS, R. D.; PEREIRA, L. G. R.; NEVES, A. L. A. AZEVÊDO, J. A. G.; MORAES, S. A.; COSTA, C. T. F. Características agronômicas de variedades de milho para produção de silagem. Acta Scientiarum. Animal Sciences, v. 32, n. 4, p. 367-373, 2010. 
SILVA, K. F.; LÁZARO, R. L.; SARTO, M. V. M.; DUARTE JÚNIOR, J. B.; OLIVEIRA, P. S.R.; COSTA, A. C. T. Produção de silagem de milho cultivado em sucessão a adubos verdes. In: CONGRESSO NACIONAL DE MILHO E SORGO, 28., 2010. Goiânia: Associação Brasileira de Milho e Sorgo, 2010. CD-Rom.

UATE, J. V.; PINHO, R. G. V.; CANCELLIER, L. L.; CAMILO, A.; BERNARDO JÚNIOR, L. A. Y. Épocas de semeadura e distribuição espacial de plantas na produção de milho. Revista Brasileira de Milho e Sorgo, v. 14, n. 3, p. 346-357, 2015.

\section{Sobre os autores:}

Rivanildo Júnior da Silva Soares: Engenheiro Agrônomo pela Universidade Federal do Cariri (UFCA).E-mail: rivanildo.agro@gmail.com

Antonio Alves Pinto: Graduando em Agronomia Universidade Federal do Cariri (UFCA). E-mail: antonioalvesaap01@gmail.com

Felipe Thomaz da Camara: Professor Adjunto na Universidade Federal do Cariri (UFCA). E-mail: felipe.camara@ufca.edu.br

Laudeline Dantas Santana: Graduanda em Agronomia pela Universidade Federal do Cariri (UFCA).

E-mail: laudelinedantas@gmail.com 
